\title{
ANALYSIS OF CROSS-SECTIONAL LAYERS OF CORROSION USING METALLOGRAPHIC MICROSCOPE
}

\author{
Barbara SZALA ${ }^{1}$, Elżbieta GREINER-WRONA ${ }^{2}$ \\ \& Monika KWAŚNIAK-KOMINEK ${ }^{1}$
}

${ }^{1}$ AGH University of Science and Technology, Faculty of Geology, Geophysics and Environmental Protection; al. Mickiewicza 30,30-059 Krakow, Poland; e-mail: basia.szala@gmail.com,kwasniak@geol.agh.edu.pl ${ }^{2}$ AGH University of Science and Technology, Faculty of Materials Science and Ceramics; al. Mickiewicza 30, 30-059 Krakow, Poland;

e-mail: egrwrona@agh.edu.pl

\begin{abstract}
The aim of this study was to identify and recognize the phenomena of corrosion between glass-metal connections. Experiments were carried out on historical and contemporary samples treated with corrosion catalysts and the results helped to identify the most corrosive conditions for historic objects. Microscopic observations were carried out on cross-sectional layers of specially prepared samples of enamel on copperplate, corresponding to the chemical composition of historic samples-enamel from Limoges. Subsequently, a series of techniques were implemented improving the quality of the image. A 20-micron thick corrosion layer can be observed and recorded using this method. Observations allowed to determine the quality and technology aspects of the enamel exposed to the processes. The diagnosis of corrosion processes is extremely important in order to determine the application technique of enamel on the metal substrate.

Microscopic images therefore revealed the formation of corrosion products. This proved an efficient and effective way to provide information on the thickness, color and structure of the observed layers. Micro-photographs from a metallographic microscope allowed for further planning and the subsequent use of a Scanning Electron Microscope (SEM) with an Energy Dispersive Spectrometer (EDS) and Raman Spectrometer (RS) - mitigating the need for the analysis of the entire sample's surface. Most corroded places have been identified and the metal proved to be more reactive material. The impact of factors such as: the technique of layering the enamel, structural inclusions, pitting corrosion, temperature and the environment's impact have been clearly linked to the overlap of the corrosion processes.
\end{abstract}

Key words: corrosion, enamel on copperplate, glass-metal, corrosion build-up, metallographic microscope, cross section of corrosion products 


\section{INTRODUCTION}

All materials are the subject of deterioration over time. On the surface of these materials, products of corrosion appear. The external environment, the temperature, the material from which the object is made and its history, all affect the corrosion mechanisms on the surfaces of materials (Greiner-Wrona 2005). In the case of the glass coating (enamel) applied to the metal substrate, its application technique provides an additional factor that affects the overlap of corrosion processes (Siwulski \& Nocun 2008). At first, the changes are not noticeable. Unfortunately, when macroscopic observations first show signs of corrosion, it is often too late to save the object or for it in to maintain its condition (Pinasco et al. 2007). It is therefore very important that modern techniques are adapted, improved and implemented to identify the mechanisms leading to corrosion. If this process is followed, it is possible to identify corrosion in the early stages.

It is crucial to identify the most harming environment for each group of materials. The key is to determine what is the first reason causing the appearance of corrosion layers of the objects. Corrosion processes depend on the chemical composition of the materials used. The weakest materials corrode first, subsequently leading to further reactions (Ekserdjian 2002). In the case of glass-metal objects, metallic material appears to be less resistant for advancing corrosion mechanisms. Despite this, copperplate has a greater resistance to relative humidity and the first corrosion products appear on a metal substrate (Drayman-Weisser 2003). When the glass corrodes very slowly, the corrosion processes occurring on metal parts manifest themselves very quickly (Scott 2002). Firstly, metal corrosion is observed (Greiner-Wrona 2012). Considering the example of enamel from Limoges, the inhibitor for further reactions may be corrosion of copperplate.

Identification of a harmful environment allows museums and proprietors of historical artifacts containing glass-metal connections to determine the appropriate storage conditions for the object. Research on the objects is unfortunately not without its limitations. The quantity and quality of the material submitted for testing is critical. Design work is determined based upon whether or not the material can be damaged during the testing process (Greiner-Wrona 2011). As a result of this, a glass sensor replicating a historical piece was used. The "glass sensor" method allows us to enforce corrosion on the object (using various mediums), and to carry a plethora of tests (Greiner-Wrona 2010). The chemical composition and production style reflects the properties of the original object. Research was conducted to explain the phenomenon of enamel-metal corrosion on an example of Limoges enamel exposed in its normal surroundings in Ranger's House, London. Results were used to plan maintenance work and to determine the optimal storage conditions (sustainable conservation).

The painted enamels, produced during the Renaissance period in Limoges, are unique and extraordinary because of their figurative composition and creative achievements. Their uniqueness is also apparent given the technological knowledge about melting and the expansion properties of the glass flux that the workshops had (Speel \& Bronk 2001). The enamels can show signs of deterioration, induced through the chemical composition of 
the enamels, humidity, temperature and atmospheric pollution. The implications can be irreversible loss of material, changes in color and transparency of the glass (Bonne et al. 1998).

Observations made using a metallographic microscope, made it possible to diagnose corrosion layers forming between the enamel and copper. Suitable sample preparation aided observations of the formed layers, with a thickness in the range of micrometers (Northover 2008). In addition to this, the thickness of the corrosion layer and the color of the crystallites can be determined. The color and location of the layer may be the first indication towards identifying the arising oxides. Through microscopic observations, the places of interest - in terms of further analysis - can be identified in order to avoid futile and time-consuming studies using highly sophisticated analytical techniques being carried out at random (Adriaens \& Dowsett 2004). Metallographic microscopy is often used in the study of rocks and minerals. The method is also extremely important in metallurgy and archaeological research on the metals and their alloys (Fulforda et al. 2004). Adapting methods to this research has proved to be extremely useful.

\section{MATERIALS AND METHODS}

Using the glass sensor, as opposed to the original historical piece allowed for an unlimited number of tests to be performed. To reenact the natural deterioration of the material (representing a combination of enamel on copperplate), corrosion was induced by immersing a sample in $20 \%$ formaldehyde solution. A corrosive agent was selected based upon previous studies on glass corrosion in the environment of organic pollutants (Robinet et al. 2006). A glass sensor on copperplate was created based the chemical composition and the application technique of the original enamel from Limoges. Corrosion processes correspond to changes in the original object which have been forced by the use an organic substance-formaldehyde. The total period of induced corrosion was 38 weeks. In addition to this, periodically, sample was boiled and stored at an elevated temperature. The parameters used in the experiment made it possible to accelerate and intensify corrosion through the more effective activation of chemical processes. It should be noted that the chosen medium, formaldehyde, was selected on the basis of factors affecting the enamel from Limoges. The application of such techniques reflects the rapidly changing parameters under real conditions in the museum's showcase. Corrosion processes begin under the influence of some factor such as elevated temperatures, strong light and the local environment. These factors may be the activation energy required for the occurrence of corrosion processes. Any deviation from the norm to the object (spot lighting leading to an increase in temperature/humidity) results in the commencement or acceleration of the reaction on the surface of the material (Greiner-Wronowa et al. 2012). The use of parameters such as temperature, light and formaldehyde solution have catalytic properties resulting in rapid reactions. Therefore, the study was conducted in physical conditions that reflect the real exhibiting location. After 38 weeks, sample in formaldehyde, including over 18 days (432 hours) at an 
elevated temperature of up to $45^{\circ} \mathrm{C}$, stereoscopic observations were made (stereoscope Leica Wild M8). Corrosion products were digitally photographed by using a digital single-lens reflex camera installed on the microscopes. Pictures taken with the stereoscope represent the shape, color and relative position of the object. Therefore, the observer has the impression of the subject in a three-dimensional form. After diagnosing the areas most affected by corrosion, it was possible to select the cross-section to be cut for sample preparation.

In order to prepare the most representative sample for the whole object and expose the rusted areas, it was extremely important that the chosen method of treatment did not destroy the corrosion layers. A rotary blade was used to cut the sample. Therefore, enamel applied to a substrate of copperplate was visible and a corrosion layer formed on the materials' surface and between the materials (Fig. 1). Then, the cut element was attached to the clip and immersed in a two-component epoxy resin, which was left to dry at $40^{\circ} \mathrm{C}$ for 24 hours. Cured samples became insoluble and infusible and gained good chemical resistance and a satisfactory picture of the sample was achieved by grinding and polishing it. In order to align the surface, a grinder with a speed $300 \mathrm{rpm}$ was used. The sample was cooled quickly with water during grinding. Initially, a 240-grit sandpaper was used, then the amount of grain was increased to 400 and 600 . The final material used for rotary grinding was 1000-grit sandpaper. To polish the sample, chemically inert diamond spray was used; the sample was then washed with ethylene alcohol to clean the surface. When using a high concentration of alcohol (96\%), the solution rapidly evaporates from the sample without causing further changes. Being prepared this way, the sample avoided any visible scratches and/or smudges produced during cutting and grinding, therefore, the resulting image was perfectly smooth.

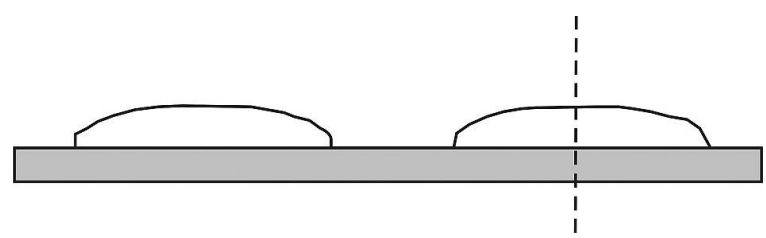

Fig. 1. Schematic diagram showing the cutting plane of sample $\mathrm{E}$ (enamel placed on the copperplate immersed in $20 \%$ formaldehyde $\mathrm{HCHO}$ )

Metallographic microscopic observations were conducted at the University of Genoa, using metallographic microscope MET 3. Stratifications were observed using a light reflecting metallographic microscope at a magnification ranging from $100 \times$ to $400 \times$.

\section{RESULTS AND DISCUSSION}

\section{Weight changes}

A decrease in the weight of the sample was observed, with the differences approximately $10^{-3} \mathrm{~g}$. With the initial sample weighing $0.718 \mathrm{~g}$ such a change is equal to around $1.3 \%$. 
Changes in the sample's weight verified the corrosion processes taking place on the weakest material - metal. It was confirmed by mass spectrometry analysis of the formaldehyde solution. The solution of formaldehyde was examined after 38 weeks of enforced corrosion and shows high copper concentration, at almost $30 \mathrm{mg} / \mathrm{L}$. The corrosion process caused the enamel to drop off from the copperplate and the exposed metal freely reacts with the formaldehyde in the environment.

\section{Stereoscopic observation}

Three areas of corrosion are visible in the pictures. This demonstrates the overlapping of different chemical reactions depending on the proximity to the glass (Fig. 2A). In addition to this, the glass enamel drops detached, showing corrosion products deposited on the edges (Fig. 2B). The most likely cause of the micro-crack was the formaldehyde solution which penetrated into the enamel, initiating a series of chemical reactions. When corrosion products began to accumulate, the blue enamel was detached from the copperplate (Fig. 2C). Also visible, is the cracking of the blue enamel structure (Fig. 2C). Stereoscopic images of the sample allowed for the identification of the place where the cutting plane will be carried out and this formed the sample for metallurgical microscopic observation.

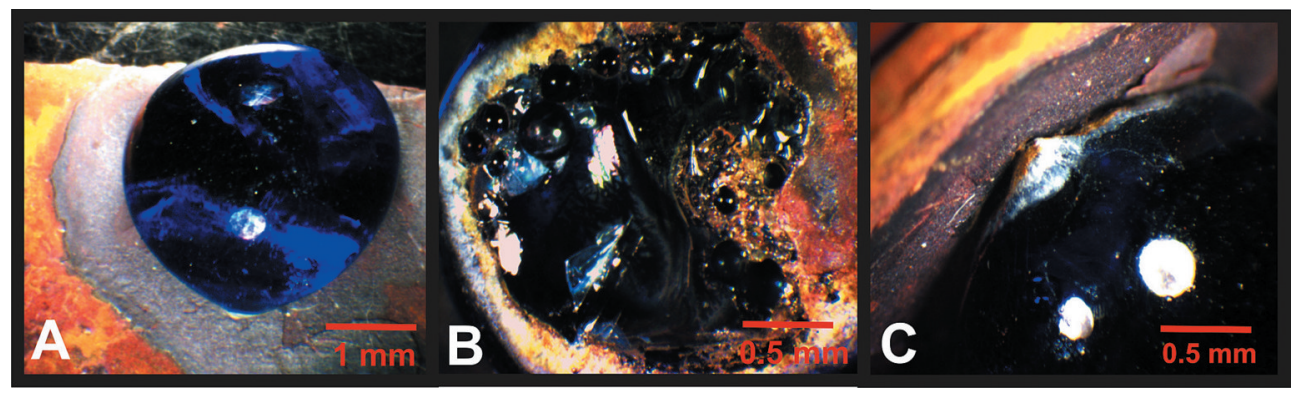

Fig. 2. Picture of sample under stereoscope, Leica Wild M8: A) enamel on copperplate corrosion areas, depending on the proximity to the enamel; B) deposit of corrosion after enamel detached from copperplate; $\mathrm{C}$ ) an increase in corrosion products between the glass and metal

\section{Metallographic microscope observation}

During observation, the corrosion thickness, depending on the distance from the position of the enamel, was clearly visible. Figure 3A shows the area where the thickness of the buildup changed drastically. By increasing distance from the glassy material (blue enamel), the corrosion layer was even 4 times thicker. This proves that of the mechanism of corrosion was specific to glass-metal objects. This suggests a much more intensive process at the border of the glass-to-metal as well as within, where the ions originating from corroding glass and metal may react. Another photograph confirmed the observed phenomenon 
(Fig. 3B). The corrosion layer formed directly between the enamel and copper substrate is much thicker. Additionally, they can be described as red crystallites, aiding the formation of copper oxide- $\mathrm{Cu}_{2} \mathrm{O}$. White inclusions, which can be interpreted as reaction products of organic substances with the elements of glass/metal are also visible. This area was subjected to further testing using a Scanning Electron Microscope with an Energy Dispersive X-ray Spectrometer (SEM/EDS) and Raman Spectrometer.

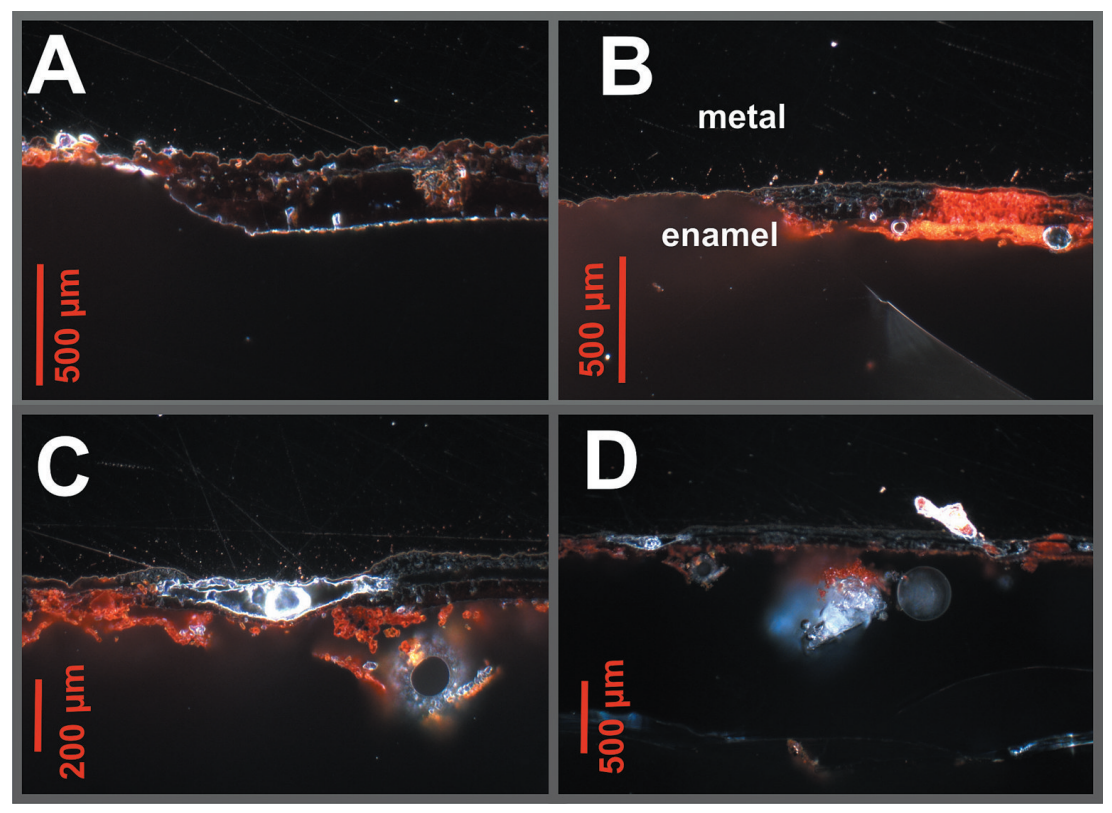

Fig. 3. Observation of the sample under a metallographic microscope MET 3 (blue enamel on a metal surface, immersed in $20 \%$ formaldehyde): A) layer of corrosion; dependency of corrosion layer thickness on the distance from the enamel; B) corrosion layer between enamel and copper; C) inclusions and bubbles in the glass structure; D) pitting corrosion; the pits in the surface are of the enamel and metal

At the time of observation, the presence of inclusions recorded bubbles (Fig. 3C). This is valuable information pertaining to technology and methods of the applied enamels on metal substrates. Their presence suggests a negligent application of enamels on copperplate, which may result in the entry of the solution under a layer of enamel and, consequently, the dispensing of this enamel. This in turn activates more corrosion mechanisms, such as pitting corrosion, which occurs when a solution enters a narrow crack and penetrates the inside of the material - a process which self-perpetuates. Then, areas further away from the surface are penetrated, causing further degradation of the material. This phenomenon is seen in the form of corrosion products that worked their way across the metal and enamel (Fig. 3D). 
Photographs taken suggest possible oxidation reactions (metal to oxide), drawing attention to the growing area of corrosion and the buildup of crystallites between the copper and enamel. As a result of these events, one of the two drops of enamel lost its adhesion to the substrate and disconnected.

\section{CONCLUSIONS}

Metallographic microscope photographs illustrate the overlap of corrosion. Apart from generally basic information, such as the color and thickness of the corrosion layer, it can attempt to determine the structure of generated crystallites. The thickness depending on the distance from the position of enamel, was also determined. In addition to this, the identification of metallic and glassy areas and observation of inclusions, cracks and blisters allowed us to determine the history of an object. Microscopic observations using a metallographic microscope - its speed, its low cost in comparison with other methods and a array of information may be obtained proved to be undoubted advantages.

An analysis of the cross section was used for the planning of further, more detailed studies using Scanning Electron Microscope with Energy Dispersive X-ray Spectroscopy (SEM/EDS), Raman Spectroscopy (RS), and Inductively Coupled Plasma Mass Spectrometry (ICP-MS). After the microscopic observation - where outbreaks of corrosion were initially diagnosed - further tests have been conducted only on the areas of interest. This made it possible to reduce the number of points subjected to special analysis. The initial diagnosis using microscopic observation was very fruitful, but had some drawbacks. To prepare the sample for cross-sectional observations, the material was destroyed. However, only a small amount of the sample needs to be prepared on the surface for observation.

Many thanks to Prof. Paolo Piccardo from the University of Genoa, as foreign internship supervisor, for his assistance in the project and for the procurement of equipment.

The research was financed by the AGH University of Science and Technology statutory grant no. 11.11.160.365/2013.

\section{REFERENCES}

Adriaens A. \& Dowsett M.G., 2004. Electron microscopy and its role in cultural heritage studies. Comprehensive Analytical Chemistry, 42, 73-128.

Bonne D.G., Biron I. \& Trocellier P., 1998. The origin of the degradation of painted enamels. Interim Meeting of the ICOM-CC Working Group, Vantaa 13-16 September 1998, Vantaa.

Drayman-Weisser T., 2003. Enamels of Limoges in the walters art museum: historical context and observations on past treatments. Journal of the American Institute for Conservation, 42, 2, 279-312. 
Ekserdjian D., 2002. Analysis of Limoge Enamels from Wernher Collection at Rangers House. Apollo Magazine, annual edition, 8-14.

Fulforda M., Sim D., Doig A. \& Painterb J, 2005. In defence of Rome: a metallographic investigation of Roman ferrous armour from Northern Britain. Journal of Archaeological Science, 32, 2, 241-250.

Greiner-Wronowa E., Thickett D. \& Rajchel B., 2012. Study of enamel degradation on copper relief. $4^{\text {th }}$ Biennial experts' meeting on Enamel on metal conservation, Abstract, Barcelona $14^{\text {th }}-15^{\text {th }}$ June 2012, Museu d'Història de Catalunya, Barcelona.

Greiner-Wronowa E., 2011. Influence of Organic Pollutants on Deterioration of Antique Glass Structure. Acta Physica Polonica, 120, 4, 830-811.

Greiner-Wronowa E., 2005. Metoda sensorów szklanych w analizie przemian chemicznych korozji szkła. Świat Szkła, 5, 64-67.

Greiner-Wronowa E., 2010. Sensory szklane - metoda wczesnego monitorowania mikroklimatu w muzeum. Szkło i Ceramika, 3, 12-17.

Northover P., 2008. Encyclopedia of Archaeology. Elsevier, Amsterdam.

Pinasco M. R., Ienco M.G., Piccardo P., Pellati G. \& Stagno E., 2007. Metallographic approach to the investigation of metallic archaeological objects. Annali di Chimica, 97, 7, 553-574.

Robinet L., Coupry C., Eremin K. \& Hall C., 2006. Raman investigation of the structural changes during alteration of historic glasses by organic pollutants. Journal of Raman Spectroscopy, 37, 1278-1286.

Scott D.A., 2002. Copper and Bronze in Art: Corrosion, Colorants, and Conservation. Getty Publications, Los Angeles.

Siwulski S. \& Nocuń M., 2008. Korozyjna degradacja powłok szklistych. Ceramika, 103, 2, 1357-1364.

Speel E. \& Bronk H., 2001. Enamel painting: Materials and Recipes in Europe from c. 1500 to c.1920. Berliner Beiträge zur Archäometrie, 18, 43-100. 